\title{
Growth performance of hybrid poplar clones on two agricultural sites with and without early irri- gation and fertilization
}

\author{
Neil D. Nelson ${ }^{*}$, Richard Meilann, William E. Berguson ${ }^{1}$, Bernard G. McMahon' ${ }^{1}$, Meijun Cai ${ }^{1}$, and \\ Daniel Buchman'
}

\begin{abstract}
${ }^{1}$ University of Minnesota Duluth NRRI, 5013 Miller Trunk Highway, Duluth, MN 55811-1442
${ }^{2}$ Department of Forestry and Natural Resources and Purdue Center for Plant Biology, 715 W. State Street, West Lafayette, IN 47907-2061

* Corresponding author: Neil D. Nelson, E-mail: nnelson2@d.umn.edu; Richard Meilan, E-mail: rmeilan@purdue.edu, ORCID: 0000-0002-8680-1110 (R.M.)
\end{abstract}

\begin{abstract}
Growth, clone rank, genotype $\mathrm{x}$ environment interaction, and effects of early fertilization and irrigation were evaluated for 56 hybrid poplar clones after three years' growth on two agricultural sites in Indiana, USA. Forty-eight percent of the clones were Populus deltoides $x$ P. nigra (DxN) crosses made with a female parent of Minnesota provenance, with the hybrids or female parent screened in Minnesota for survival, growth rate, and disease tolerance or resistance. Forty-one percent of the clones had at least one parent from provenances that are more southerly and/or have more moderate climates of provenance origin than Minnesota. Eleven percent of the clones were screened in Minnesota but were either not DXN crosses or did not have parents from Minnesota provenances in their parentage. Height growth averaged $1.78 \mathrm{~m}$ per year for all clones over all treatments and $2.02 \mathrm{~m}$ per year for the fastestgrowing six clones (top $10^{\text {th }}$ percentile). Tree bole volume for the fastest-growing $10 \%$ of the clones was $70 \%$ larger than the average of two commercial standard clones. The clonal effect was dominant in comparison to site, treatment, and interaction effects. The fertilizer, irrigation, and fertilizer $x$ irrigation treatments tended to increase growth, but the statistical significance of the treatment effects differed by site, and the treatments explained only a small portion of the variance. Clone rank was the same on both sites, regardless of treatment, except for the fertilizer $\mathrm{x}$ irrigation treatment. DxN clones linked to Minnesota parentage out-performed most clones of more southerly or other more moderate climatic origins, in these tests conducted far south of Minnesota. The data provide further evidence of broad adaptability of DxN hybrids with female $P$. deltoides parents of Minnesota
\end{abstract}

provenance, possibly eliminating the need for narrow breeding zones and reducing the number of screening tests needed at different latitudes, saving time and money. Tests are planned to further analyze and possibly extend this inference.

Keywords: hybrid poplars, Populus, irrigation, fertilization, genotype $x$ environment interaction, breeding

\section{Introduction}

The potential for achieving one billion dry tons of cellulosic biomass per year nationally by 2030 as specified in the DOE 2016 Billion-Ton Report will require the production of more than 239 million dry tons from dedicated energy crops (US DOE 2016). Poplar (Populus spp.) culture has significant potential to help meet this target, and the Midwestern United States has the capacity to be a major contributor due to adequate rainfall and land availability.

The realization of this potential may require improved hybrid poplar genetic material that has superior and robust growth over a variety of geographic regions, soils, and climates (Nelson et al., 2018) due to the large capital requirement for narrow breeding zones. A low genotype $x$ environment interaction would be cost efficient and operationally favorable. A hybrid poplar clonal trial established on agricultural soils on two Midwestern USA sites (northern and southern Indiana) in 2011 provides another opportunity to identify broadly adapted clones that exhibit superiority in growth rates on dissimilar sites. This study also can contribute to a better understanding of the relative strengths of clone and clone $x$ environment 
(GxE) effects for improved populations of poplar. Early fertilization and irrigation treatments were tested on both sites to determine whether clone ranks and GxE interaction changed within or between test sites in response to these treatments. A comparison of the results obtained in this pair of trials was made with similar trials in Minnesota, USA.

The fertilizer, irrigation, and fertilizer $x$ irrigation treatments in this study were designed to test nutrient and water stress amelioration on clonal performance and were not intended to represent commercial operations. Although fertilizer applications in poplar production plantations are sometimes done early in the rotation as in this study, the preferred method is application at crown closure (Coleman et al., 2006). Irrigation has been used in commercial poplar plantations in semi-arid areas of Oregon, USA (Stanton et al., 2002), but irrigation is unlikely to be used in the eastern and central portions of the Midwestern United States, where rainfall is plentiful.

Studies within Populus and other tree genera show a broad pattern of growth being limited by nutrient availability, with response to nutrient amelioration dependent on adequate soil water availability (Linder, 1989). Fertilizer application in poplar plantations can increase growth from 20 $\%$ to $60 \%$ on poorer sites, but it has little or no effect on some better sites (Coleman et al., 2006 and citations within). Significant growth benefits from irrigation of poplars have been demonstrated for sites in humid temperate climates (Hansen 1988; Dickmann et al., 1996; Moffat et al., 2001). Coyle and Coleman (2005) and Samuelson et al. (2007) reported positive effects of fertilization and irrigation on growth of $P$. deltoides but no interaction of fertilization and irrigation. A positive interaction of fertilization and irrigation on poplar growth was documented by van den Driessche et al. (2003).

Twenty-one of the DxN clones in our study were bred by the Natural Resources Research Institute (NRRI) Poplar Program, which is based at the University of Minnesota Duluth, and tested and selected in northern Minnesota at 46 to 48 degrees north latitude. The P. nigra parents of the NRRI DxN clones were from populations screened in Ontario, Canada. Six of the DxN clones derived from other breeding programs also had female $P$. deltoides parents of Minnesota provenance, with the female parent but not the hybrids screened in Minnesota. The Indiana sites were at 41.4 and 38.7 degrees north latitude, a difference of 5-9 degrees latitude and 7-9 degrees longitude from the sites used to initially test and select the NRRI DxN clones.

The objectives of this study were to: (1) analyze the effects of site, clone, and clone $x$ site interaction with and without early fertilization and irrigation on the growth performance of hybrid poplar clones of different origins; (2) determine of the effects of site, fertilization, and irrigation on clone rank; (3) investigate the effect of parental origins on clone rank; and (4) seek inferences on GxE interactions and the strength of genetic control of growth rate by comparing the results with other studies involving the same clones.

\section{Materials and Methods}

\section{Plant material \\ Clone selection for tests-}

Fifty-six clones were included in the tests (Table 1). Forty-eight percent of the clones were Populus deltoides $x$ P. nigra (DxN) crosses made with a female parent of Minnesota provenance, with the hybrids or female parent screened in Minnesota for survival, growth rate, and disease tolerance or resistance. Most P. deltoides parents from Minnesota provenances were originally from the C.A. Mohn selection and breeding program, University of Minnesota. The NRRI P. nigra male parents of Ontario Canada origin were derived from pollen of trees tested and screened in Ontario by L. Zsuffa, University of Toronto. Forty-one percent of the clones had at least one parent from provenances that are more southerly and/or have more moderate climates of provenance origin than Minnesota. Eleven percent of the clones were screened in Minnesota but were either not DXN crosses or did not have parents from Minnesota provenances in their parentage. Two commercial standards, DN5 and NM6, were embedded in the trials. Nineteen NRRI clones were common to a previous clonal trial in Minnesota (Nelson et al., 2018).

$\underline{\text { Table } 1}$

Description of clones in this test

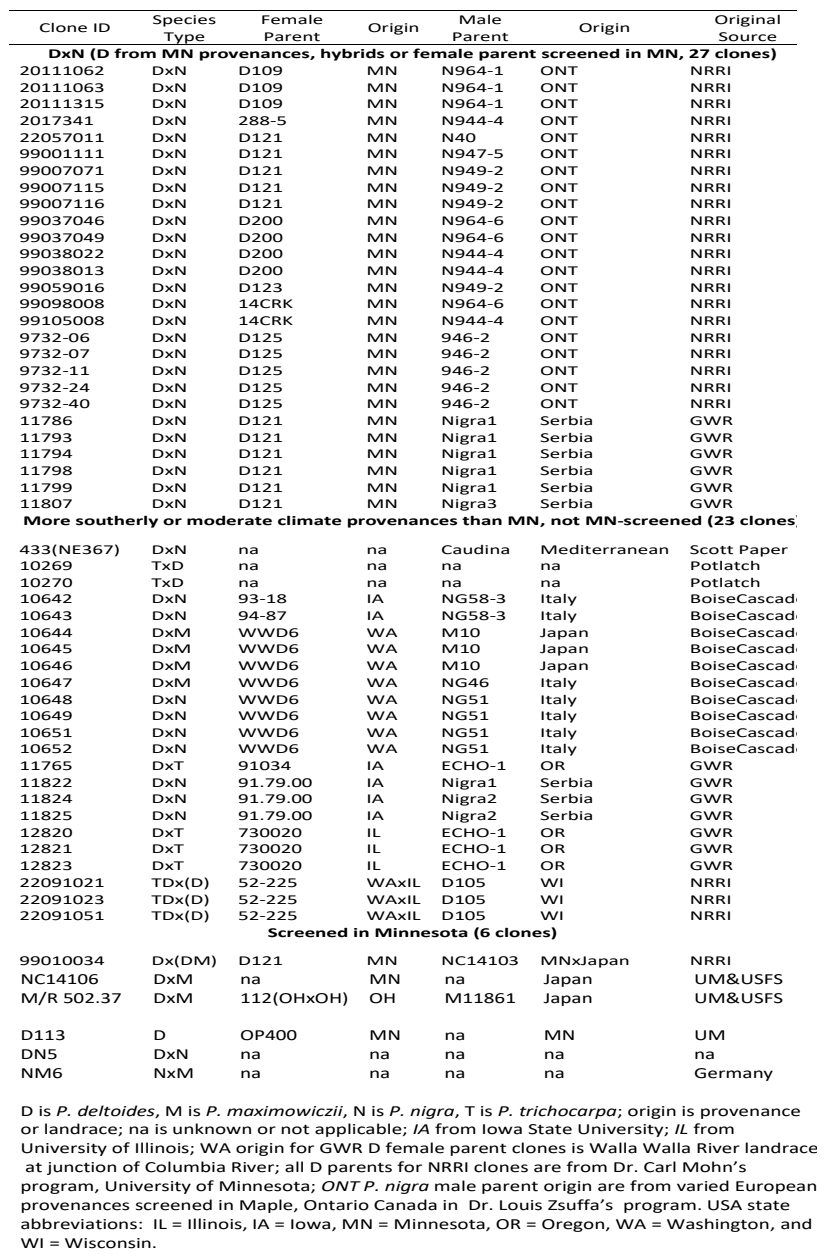




\section{Plant propagation}

Planting stock was $20-\mathrm{cm}$ unrooted dormant cuttings harvested from current annual shoots of stools (cutting orchard) and kept at $-2.8{ }^{\circ} \mathrm{C}$ ( $<4$ months) until planting. The stool beds were established and maintained near West Lafayette, Indiana, by Purdue University (R. Meilan) and ArborAmerica, LLC (G. Pardillo), using cuttings supplied by NRRI and GreenWood Resources (GWR; Portland, Oregon, USA) Clones were screened and selected for the tests based on performance in the stool beds and stock availability as a de facto vigor pre-screening.

\section{Study locations}

The two test sites, both of which are in Indiana, USA, were: the Southwest Purdue Agricultural Center (SWPAC; https:// ag.purdue.edu/arge/pac/Pages/swpac-home.aspx), $\quad 38.7$ degrees N latitude, -87.5 degrees longitude, and PinneyPurdue Agricultural Center (PPAC; https://ag.purdue.edu/arge/ pac/Pages/ppac-home.aspx),41.4 degrees N latitude, -86.9 degrees longitude. The geography and information on soils and climate for the test locations are in Table 2. Test plots on both sites were on normal agricultural soils

Table 2

Location, soil, and climate information for the Indiana test sites

\begin{tabular}{lcc}
\hline & \multicolumn{2}{c}{ Site } \\
& SWPAC & PPAC \\
\hline County & Knox & LaPorte \\
Nearest town & Vincennes & Wanatah \\
Latitude & 38.737894 & 41.441828 \\
Longitude & -87.484995 & -86.923137 \\
Slope\% & 10 to 18 & 0 to 2 \\
Soil texture & silt clay loam & sandy loam \\
Soil pH & 5.3 & 5.0 \\
Soil particulate organic matter (\%) & 0.67 & 1.33 \\
Soil bulk density (g/cm3) & 1.46 & 1.56 \\
Crop Productivity Index (CPI) & 107 & not available \\
Average high/low temperature (C) & $31.1 /-6.1$ & $28.3 /-10.6$ \\
Growing degree days (GDD, base 10C/30C) & 3900 & 3050 \\
Average precipitation (mm) & 1170 & 1015 \\
Average annual precipitation for study years & 1303 & 827 \\
2011-2013 (mm) & & \\
\hline
\end{tabular}

1) Soil data from https://websoilsurvey.sc.egov.usda.gov/App/HomePage.htm

CPI from Olson et al. 2000. 2) Climate data from https://www.usclimatedata.com/ U.S. Climate Data, threedecade (1981-2010) averages (National Centers for Environmental Information, NOAA). 3) Crop Productivity Index explanation reference (Dobos et al. 2012). 4) GDD https://mrcc.illinois.edu/gismaps/gddinfo.htm

\section{Plantation establishment and maintenance}

The sites were planted in spring 2011. Approximately one month prior to planting at PPAC, the site was prepared by using conventional tillage with a disk and a field cultivator. Three days before planting, Roundup ${ }^{\circledR}$ WeatherMax was applied over the plant-rows at a rate of $1.61 \mathrm{l} / \mathrm{ha}$, along with a follow-up application of $\operatorname{Prowl}^{\circledR} \mathrm{H}_{2} \mathrm{O}$ at a rate of $7 \mathrm{l} / \mathrm{ha}$. About one month before planting at SWPAC, the site was prepared by making a banded application of Roundup ${ }^{\circledR}$ Power Max herbicide at a rate of $2.34 \mathrm{l} / \mathrm{ha}$; a repeat application was made approximately two weeks later. Two days prior to planting Framework ${ }^{\circledR}$ 3.3EC herbicide was applied over the rows at a rate of $2.34 \mathrm{l} / \mathrm{ha}$. At both locations, a trickle-irrigation line ( $T$ tape) was buried at the center of each plant-row at a depth of $8-10 \mathrm{~cm}$.

Cuttings were planted at a spacing of $2.4 \mathrm{~m}$ within rows and $1.8 \mathrm{~m}$ between rows. A 2.3-m high plastic mesh deer fence (Deer Busters fencing, 650-lb breaking strength) was erected around the perimeter of each trial.

Weed control between rows after the trees were established consisted of mowing every 3-4 weeks, as needed, throughout the first three years. Weed control within rows was performed by applying undiluted Roundup ${ }^{\circledR}$ (glyphosate) with an ultralow-volume Mankar sprayer twice in year 1.

\section{Study design}

The experiment was a completely randomized design of multiple single-tree plots nested within four cultural treatment plots (blocks) at two sites. There was no replication of cultural treatments within each site. A different treatment was applied to each of the four cultural treatment blocks at each site for the first two growing seasons: Fertilization only, Irrigation only, Fertilization + Irrigation, and no fertilization or irrigation (No Treatment). For the first two years, $60 \mathrm{~g}$ of Osmocote ${ }^{\circledR}$ fertilizer (Scotts Miracle-Gro, 15-9-12) was applied in early spring to the Fertilizer and Fertilizer + Irrigation blocks to a small hole dug at the base of the planted cuttings. Irrigation was applied on an as-needed basis, at the discretion of the agronomist in charge of each experimental farm. Irrigation and fertilization were discontinued after the second growing season.

Clones were randomly assigned within each block, but in a way that ensured equal numbers of ramets of each clone in odd- and even-numbered rows within each block. A border row was established around the outer perimeter of each block, but not between adjoining blocks, using cuttings from a randomized assortment of genotypes. Fertilizer and Fertilizer + Irrigation treatment blocks were not adjacent. Fertilizer + Irrigation and Irrigation blocks were adjacent, as were No Treatment and Fertilizer blocks. There was a $4.9 \mathrm{~m}$ alley between the Irrigation and No Treatment blocks. Diffusion of fertilizer into adjoining Irrigation and No Treatment blocks was minimized by the use of slow-release fertilizer, which was applied to the soil at the base of each cutting as described below. The positioning of the Fertilizer + Irrigation and Irrigation blocks adjacent to each other minimized any "spillover effect" resulting from water diffusing into adjacent blocks. The clones from GWR were replicated six times within each block. Clones from the NRRI were replicated 10 times within each block.

\section{Measurements}

Growth data (height and diameter) and survival for all except border trees were taken at the end of each growing season (2011, 2012, and 2013) after the trees had gone dormant. Diameter at breast height ( $\mathrm{DBH}, 1.4 \mathrm{~m}$ above ground level) was measured with 45.7-cm Haglöf Mantax aluminum calipers. A Tel-O-Pole ${ }^{\circledR}$ measuring stick (Hastings, model E35) was used to 
obtain tree heights. Tree bole volume outside bark after three growing seasons was calculated by the equation developed for plantation cottonwood ( $P$. deltoides) by Krinard $(1988)=0.06+$ $0.002221 \mathrm{D}^{2} \mathrm{H}\left(\mathrm{r}^{2}=0.987\right)$, where $\mathrm{D}$ is $\mathrm{DBH}$ and $\mathrm{H}$ is total tree height. This regression uses diameter in inches and height in feet to derive cubic feet. Cubic feet volume was then converted to $\mathrm{cm}^{3}$. The emphasis of this study was on biomass production. Consequently, stem straightness and other log-quality parameters were not evaluated.

\section{Statistical analyses}

Means and ranks for total tree volume were calculated for each clone on each site at age 3 (end of third growing season). Frequency plots of tree volume by site and type of treatment exhibited a right-skewed distribution. A $\log _{10}$ transformation was applied to the volumetric data, resulting in a near-normal data distribution. Therefore, $\log _{10}$ tree volume was used as the response variable throughout the analyses.

Data from the two sites were combined and analyzed by a sequence of two ANOVA procedures. The initial ANOVA was performed in SAS 9.4 according to a linear mixed model treating site, treatment (irrigation, fertilization), and site $x$ treatment interaction as fixed variables and clone and any interaction with clone (site $x$ clone, treatment $x$ clone, and site $x$ treatment $x$ clone) as random variables.

The model had a significant $\mathrm{R}^{2}$, and all effects were significant in the initial ANOVA except treatment $x$ clone and site $x$ treatment $x$ clone (see Results). Thus, the latter two interactions were excluded from the predictor list, and a new ANOVA final model was developed using the remaining five significant variables: site, treatment, clone, site $\mathrm{x}$ treatment, and site $x$ clone. The final ANOVA was a mixed-model analysis performed in R 3.5.1 using the software package $1 \mathrm{me} 4$. Random variables were clone and clone $\mathrm{x}$ site. Variance components for fixed and random effects were calculated as percentages of total variance in the final ANOVA model.

Heritabilities for the clonal population pooled across both sites were calculated as follows:

Broad-sense heritability, $\quad H^{2}=\frac{\sigma_{A}^{2}+\sigma_{I}^{2}}{\sigma_{A}^{2}+\sigma_{I}^{2}+\sigma_{E}^{2}}$,

Narrow-sense heritability, $h^{2}=\frac{\sigma_{A}^{2}}{\sigma_{A}^{2}+\sigma_{I}^{2}+\sigma_{E}^{2}}$,

where $\sigma_{A}^{2}$ is the additive genetic variance, $\sigma_{1}^{2}$ is the nonadditive genetic variance (variance of the interaction of clone and site), and $\sigma_{\mathrm{E}}{ }^{2}$ is the error variance (variance among trees caused by micro-environmental effects) (White et al., 2007).

Overall clone rank was calculated by averaging $\log _{10}$ tree volume for each site $x$ treatment combination for each clone, followed by averaging the former means to derive a mean for each clone across the two sites. Rank 1 is the largest (fastest growing) clone; Rank 56 is the smallest clone. Spearman's Coefficient of Rank Correlation was used to determine whether clone rank changes contributed to clone $x$ site interactions. A separate Spearman's test was done for rank (basal area basis) in a previous set of clone trials in Minnesota versus rank $\left(\log _{10}\right.$ tree volume) in the current study for the $19 \mathrm{NRRI}$ clones common to both studies.

Histogram plots of tree volume indicated that variances may not be equal between the two sites or among the four treatment types. Three variance comparisons were conducted using $\log _{10}$ tree volume to determine whether variances differed by treatment for: all data, PPAC site-only treatment, and SWPAC site-only treatment. Four tests were used for these variance comparisons: O'Brien test, Brown-Forsythe test, Levene's test, and Bartlett's test. Variances were not significantly different among treatments for each site (see Results), so Tukey's HSD test was used to compare the difference among treatments within each site. Due to unequal variances between sites, the comparison of sites by treatment was tested with Wilcoxon's non-parametric test using the JMP software package.

Due to the unequal replication of NRRI clones (6) and GWR clones (10) and some relatedness between clones (only $23 \%$ of clones do not share a male and/or female parent with at least one other clone), we questioned whether to use observed clone growth values or Best Linear Unbiased Predictor (BLUP)derived clone values in the analyses. A plot of clone rank based on BLUP and observed values indicated there was no significant difference between the methods $\left(R^{2}=0.999\right)$. Therefore, we based all analyses on observed values.

\section{Results}

\section{Means and analysis of variance}

Survival measured after the third growing season was excellent, $99.7 \%$ for PPAC, $94.6 \%$ for SWPAC.

Table 3 shows the average tree height, DBH, and total volume for each site. Height growth averaged $1.78 \mathrm{~m}$ per year over the first three years of the planting for all clones over all treatments and $2.02 \mathrm{~m}$ per year for the fastest-growing six clones (top $10^{\text {th }}$ percentile). Tree bole volume for the fastestgrowing $10 \%$ of the clones was $55 \%$ larger than tree volume average for all clones over all treatments and $70 \%$ larger than the average of the two commercial check clones.

Table 3

Mean of height, diameter, and tree volume for each site after 3 years' growth. $\log _{10}$ is of tree bole volume in $\mathrm{cm}^{\underline{3}}$.

\begin{tabular}{|c|c|c|c|c|c|}
\hline Parameter & & PPAC & SWPAC & $\begin{array}{c}\text { Top } 10 \% \\
\text { clones } \\
\text { across both } \\
\text { sites }\end{array}$ & $\begin{array}{c}\text { Two } \\
\text { commercia } \\
\text { check } \\
\text { clones }\end{array}$ \\
\hline \multirow{3}{*}{ Height, $\mathrm{m}$} & Mean & 5.51 & 5.14 & 6.07 & 5.16 \\
\hline & Standard deviation & 0.82 & 1.41 & 0.94 & \\
\hline & Median & 5.6 & 5.3 & 6.16 & \\
\hline \multirow{3}{*}{$\mathrm{DBH}, \mathrm{cm}$} & Mean & 6.5 & 7.0 & 8.3 & 6.6 \\
\hline & Standard deviation & 1.4 & 2.0 & 1.8 & \\
\hline & Median & 6.5 & 6.9 & 8.0 & \\
\hline \multirow{3}{*}{$\begin{array}{l}\text { Volume, } \\
\mathrm{cm}^{3}\end{array}$} & Mean & 9,700 & 11,400 & 16,400 & 9,600 \\
\hline & Standard deviation & 3,900 & 7,400 & 8,200 & \\
\hline & Median & 9,300 & 9,800 & 14,600 & \\
\hline \multirow{3}{*}{$\begin{array}{l}\log _{10} \\
\mathrm{~cm}^{3} \text { Volume }\end{array}$} & Mean & 3.95 & 3.97 & 4.17 & 3.94 \\
\hline & Standard deviation & 0.19 & 0.28 & 0.20 & \\
\hline & Median & 3.97 & 3.99 & 4.16 & \\
\hline
\end{tabular}

Except where noted, data are for all clones over all treatments. The commercial check clones are DN5 and NM6. 
The initial ANOVA is shown in Table 4. All effects were significant except treatment $x$ clone and site $x$ treatment $x$ clone.

Table 4

Initial ANOVA. Dependent Variable: $\log _{10}$ Volume. Log is of tree $\underline{\text { bole volume in } \mathrm{cm}^{3}}$.

\begin{tabular}{lccccc}
\hline \multicolumn{1}{c}{ Source } & DF & Type III SS & Mean Square & FValue & Pr $>F$ \\
\hline Site & 1 & 0.20513605 & 0.20513605 & 6.53 & 0.0107 \\
Treatment & 3 & 5.48694017 & 1.82898006 & 58.20 & $<.0001$ \\
Clone & 55 & 74.71707519 & 1.35849228 & 43.23 & $<.0001$ \\
Site* ${ }^{*}$ Treatment & 3 & 2.26267549 & 0.75422516 & 24.00 & $<.0001$ \\
Site* ${ }^{*}$ Clone & 55 & 11.07431514 & 0.20135118 & 6.41 & $<.0001$ \\
${\text { Treatment* }{ }^{*} \text { Clone }}$ & 165 & 5.20517045 & 0.03154649 & 1.00 & 0.4729 \\
Site* ${ }^{*}$ Treatment*Clone & 165 & 5.22768376 & 0.03168293 & 1.01 & 0.4577 \\
\hline
\end{tabular}

Variance components for growth based on the final ANOVA are exhibited in Table 5 . The clone effect was $36 \%$ of total variance, almost 10 times the effect of site, treatment, and site $x$ treatment combined, and over four times the effect of site $x$ clone interaction. Experimental error accounts for over half of the variance.

Based on the variance component data in Table 5, broadsense heritability, $\mathrm{H}^{2}$, and narrow-sense heritability, $\mathrm{h}^{2}$, are:

$$
\begin{aligned}
& H^{2}=\frac{\sigma_{A}^{2}+\sigma_{I}^{2}}{\sigma_{A}^{2}+\sigma_{I}^{2}+\sigma_{E}^{2}}=\frac{0.0219+0.0054}{0.0219+0.0054+0.0314}=0.46 \\
& h^{2},=\frac{\sigma_{A}^{2}}{\sigma_{A}^{2}+\sigma_{I}^{2}+\sigma_{E}^{2}}=\frac{0.0219}{0.0219+0.0054+0.0314}=0.37
\end{aligned}
$$

Table 5

Variance components for $\log _{10}$ volume, final ANOVA. Clone, site $x$ clone, and model error are random effects.

\begin{tabular}{lcc}
\hline \multicolumn{1}{c}{ Source } & Variance components & $\begin{array}{c}\text { \% of variance } \\
\text { components }\end{array}$ \\
\hline $\begin{array}{l}\text { Fixed factors (Site, Treatment, } \\
\text { Site * Treatment) }\end{array}$ & 0.0023 & $3.77 \%$ \\
Clone & 0.0219 & $35.90 \%$ \\
Site*Clone & 0.0054 & $8.85 \%$ \\
Error & 0.0314 & $51.48 \%$ \\
\hline
\end{tabular}

Results from four methods of testing for equality of variances are displayed in Table 6. Variances were significantly different between sites but equal for treatments within each site. $\underline{\text { Table } 6}$

P-values for variance comparison by four methods. Null hypothesis is that variances are equal. P-value $<0.05$ is rejection of the null hypothesis.

\begin{tabular}{lccc}
\hline & $\begin{array}{c}\text { All data } \\
\text { Site X Treatment }\end{array}$ & $\begin{array}{c}\text { Site PPAC only } \\
\text { Treatment }\end{array}$ & $\begin{array}{c}\text { Site SWPAC only } \\
\text { Treatment }\end{array}$ \\
\hline O'Brien test & 0.0002 & 0.8676 & 0.1847 \\
Brown-Forsythe test & 0.0003 & 0.8353 & 0.1692 \\
Levene's test & 0.0002 & 0.7294 & 0.1742 \\
Bartlett's test & $<0.0001$ & 0.7990 & 0.1918 \\
\hline
\end{tabular}

The mean and standard error for $\log _{10}$ tree volume within each site and treatment type are displayed in Figure 1.

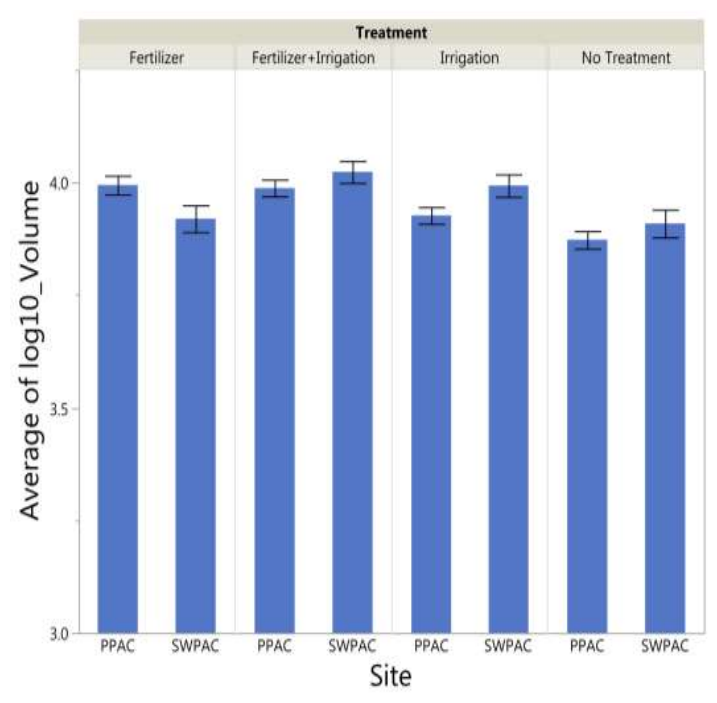

Results of Tukey's HSD test for comparing the difference in $\log 10$ tree bole volume due to treatments within each site are shown in Table 7. At PPAC, bole volume (anti-log) under Fertilizer and Fertilizer + Irrigation treatments was $32 \%$ greater and significantly different than under No Treatment. At SWPAC bole volume for Fertilization + Irrigation was $29 \%$ greater and significantly different than for No Treatment.

\section{Table 7}

The mean values of $\log _{10}$ tree bole volume in $\mathrm{cm}^{3}$ by four treatment types within each site at age 3. Data at same column sharing same letters have insignificant difference of the means based on Tukey's HSD test. Data are not comparable across the columns.

\begin{tabular}{lcc}
\hline \multicolumn{1}{c}{ Treatment type } & PPAC & SWPAC \\
\hline Fertilizer & $3.99^{\mathrm{A}}$ & $3.92^{\mathrm{B}}$ \\
Fertilizer + Irrigation & $3.99^{\mathrm{A}}$ & $4.02^{\mathrm{A}}$ \\
Irrigation & $3.93^{\mathrm{AB}}$ & $3.99^{\mathrm{AB}}$ \\
No Treatment & $3.87^{\mathrm{B}}$ & $3.91^{\mathrm{B}}$ \\
\hline
\end{tabular}


Wilcoxon's test of the significance of tree bole volume differences of mean treatment values between the two sites is in Table 8 . The only significant difference between sites for treatments was for the Irrigation treatment, wherein the SWPAC site had a larger tree volume under Irrigation than did the PPAC site.

Table 8

Wilcoxon test of site differences for mean values of $\log _{10}$ tree bole volume in $\mathrm{cm}^{3}$ for two sites within each of four treatments at age 3. Comparison is within each row, not within columns.

\begin{tabular}{lccc}
\hline \multicolumn{1}{c}{ Treatment } & PPAC & SWPAC & Probability > Chisq \\
\hline Fertilizer & 3.99 & 3.92 & 0.0634 \\
Fertilizer + Irrigation & 3.99 & 4.02 & 0.2067 \\
Irrigation & 3.93 & 3.99 & 0.0212 \\
No Treatment & 3.87 & 3.91 & 0.3141 \\
\hline
\end{tabular}

\section{Clone ranks}

Mean clone ranks are presented in Table 9. Taxa and provenance effects are summarized in Table 10. DxN clones of Minnesota provenance for the female $P$. deltoides parent with hybrids or female parent screened in Minnesota (DN-MN) dominate the top $10^{\text {th }}$ and $25^{\text {th }}$ percentiles for growth. DN-MN clones were 48 $\%$ of the total clonal population but were $83 \%$ and $71 \%$ of the $10^{\text {th }}$ and $25^{\text {th }}$ percentiles, respectively.

There was no significant rank change (Spearman's test, Table 11) between the two sites for No Treatment, Fertilizer, and Irrigation treatments. Fertilizer + Irrigation did result in significant rank change, but the $p$ value was just above 0.05 (0.07).

A surprising result of this study was the superior performance and significant representation of $P$. deltoides $x$ P. nigra (DxN) clones with a female $P$. deltoides parent of Minnesota origin within the top growth percentiles of clone rank (Table 10). We did not expect to see such broad adaptability across a northsouth gradient, and it prompted a careful evaluation of the clonal performance and GxE interaction revealed by this study, relative to past results in Minnesota.

A rank comparison of NRRI clones common to the current study and a previously reported trial in Minnesota (Nelson et al., 2018) is presented in Table 12. A Spearman's test comparing these two datasets gave a Spearman's correlation coefficient of $0.8053(p<0.0001)$, indicating no significant rank change for the two studies. One NRRI DxN clone, 99038022, was in the top 10th percentile in both studies. Three NRRI DxN clones (99038022, 20111315, and 99007116) were in the top 25th growth percentile in both studies. $\underline{\text { Table } 9}$

Mean clone rank across and within both sites based on the $\log _{10}$ mean tree bole volume in $\mathrm{cm}^{3}$ of mean site $x$ treatment values at age 3 for each clone. Rank is ordered from highest value to lowest value. Across-site values for tree bole volume are average of average site values.

\begin{tabular}{|c|c|c|c|c|}
\hline Clone & $\begin{array}{c}\text { Across both sites } \\
\log _{10} \text { volume }\end{array}$ & $\begin{array}{c}\text { Across both sites } \\
\text { Rank }\end{array}$ & $\begin{array}{l}\text { PPAC } \\
\text { Rank }\end{array}$ & $\begin{array}{l}\text { SWPAC } \\
\text { Rank }\end{array}$ \\
\hline $11807^{\mathrm{MN}}$ & 4.25 & 1 & 1 & 1 \\
\hline $99007071^{\mathrm{MN}}$ & 4.18 & 2 & 8 & 2 \\
\hline $11793^{\mathrm{MN}}$ & 4.18 & 3 & 2 & 3 \\
\hline $10642^{5}$ & 4.15 & 4 & 6 & 5 \\
\hline $99038022^{\mathrm{MN}}$ & 4.13 & 5 & 5 & 9 \\
\hline $11798^{\mathrm{MN}}$ & 4.13 & 6 & 10 & 7 \\
\hline $11794^{\mathrm{MN}}$ & 4.12 & 7 & 16 & 4 \\
\hline $433^{5}$ & 4.12 & 8 & 19 & 6 \\
\hline $20111315^{\mathrm{MN}}$ & 4.11 & 9 & 12 & 8 \\
\hline $11824^{5}$ & 4.11 & 10 & 3 & 13 \\
\hline $10648^{5}$ & 4.10 & 11 & 13 & 10 \\
\hline $99038013^{\mathrm{MN}}$ & 4.10 & 12 & 9 & 14 \\
\hline $11799^{\mathrm{MN}}$ & 4.09 & 13 & 7 & 16 \\
\hline $99007116^{\mathrm{MN}}$ & 4.08 & 14 & 11 & 15 \\
\hline $99059016^{\mathrm{MN}}$ & 4.07 & 15 & 20 & 11 \\
\hline $10270^{5}$ & 4.06 & 16 & 4 & 24 \\
\hline $11786^{\mathrm{MN}}$ & 4.05 & 17 & 22 & 17 \\
\hline $99007115^{\mathrm{MN}}$ & 4.03 & 18 & 21 & 19 \\
\hline $10649^{A}$ & 4.02 & 19 & 38 & 12 \\
\hline $20173417^{\mathrm{MN}}$ & 4.01 & 20 & 27 & 18 \\
\hline $10643^{5}$ & 4.01 & 21 & 26 & 21 \\
\hline $11825^{5}$ & 4.01 & 22 & 18 & 29 \\
\hline $22057011^{\mathrm{MN}}$ & 4.00 & 23 & 17 & 31 \\
\hline $9732-24^{\mathrm{MN}}$ & 3.99 & 24 & 31 & 22 \\
\hline $99098008^{\mathrm{MN}}$ & 3.99 & 25 & 30 & 25 \\
\hline $99037046^{\mathrm{MN}}$ & 3.99 & 26 & 23 & 32 \\
\hline $10651^{\mathrm{s}}$ & 3.97 & 27 & 34 & 26 \\
\hline $20111062^{\mathrm{MN}}$ & 3.97 & 28 & 32 & 27 \\
\hline $11822^{5}$ & 3.97 & 29 & 40 & 20 \\
\hline $10644^{5}$ & 3.96 & 30 & 14 & 43 \\
\hline $9732-11^{\mathrm{MN}}$ & 3.96 & 31 & 37 & 28 \\
\hline M/R 502.37 & 3.95 & 32 & 15 & 45 \\
\hline $99105008^{\mathrm{MN}}$ & 3.95 & 33 & 24 & 40 \\
\hline $\mathrm{DN}^{\circ}$ & 3.95 & 34 & 36 & 30 \\
\hline $9732-40^{\mathrm{MN}}$ & 3.95 & 35 & 44 & 23 \\
\hline $10645^{\mathrm{s}}$ & 3.94 & 36 & 25 & 42 \\
\hline $\mathrm{NM}^{\circ}$ & 3.94 & 37 & 35 & 33 \\
\hline $20111063^{\mathrm{MN}}$ & 3.93 & 38 & 33 & 36 \\
\hline $10646^{\mathrm{S}}$ & 3.93 & 39 & 29 & 44 \\
\hline $99037049^{\mathrm{MN}}$ & 3.92 & 40 & 39 & 34 \\
\hline $\mathrm{D} 113^{\circ}$ & 3.89 & 41 & 42 & 39 \\
\hline $9732-06^{\mathrm{MN}}$ & 3.89 & 42 & 46 & 35 \\
\hline $9732-07^{\mathrm{MN}}$ & 3.88 & 43 & 45 & 37 \\
\hline $22091021^{\mathrm{MN}}$ & 3.87 & 44 & 28 & 48 \\
\hline $10652^{5}$ & 3.84 & 45 & 48 & 41 \\
\hline $99001111^{\mathrm{MN}}$ & 3.83 & 46 & 50 & 38 \\
\hline $10647^{s}$ & 3.80 & 47 & 47 & 46 \\
\hline $22091051^{\mathrm{MN}}$ & 3.78 & 48 & 41 & 51 \\
\hline $22091023^{\mathrm{MN}}$ & 3.78 & 49 & 43 & 50 \\
\hline $\mathrm{NC} 14106^{\circ}$ & 3.73 & 50 & 51 & 49 \\
\hline $10269^{\mathrm{s}}$ & 3.70 & 51 & 52 & 52 \\
\hline $11765^{\mathrm{s}}$ & 3.70 & 52 & 53 & 47 \\
\hline $99010034^{\circ}$ & 3.69 & 53 & 49 & 53 \\
\hline $12821^{\mathrm{S}}$ & 3.60 & 54 & 54 & 54 \\
\hline $12820^{\mathrm{s}}$ & 3.53 & 55 & 56 & 55 \\
\hline $12823^{\mathrm{S}}$ & 3.52 & 56 & 55 & 56 \\
\hline
\end{tabular}

$\overline{\mathrm{MN}}$ are Populus deltoides $x$ P. nigra clones with $P$. deltoides parents of Minnesota (MN)provenances, hybrids or female $P$. deltoides parent screened in $\mathrm{MN}$. $\mathrm{s}$ are clones of more southerly or moderate climatic origins than $\mathrm{MN}$, not screened in $\mathrm{MN}$. $^{\circ}$ are other clones (non-DxN or DxN of unknown provenances, but screened in $\mathrm{MN}$ ). 
Table 10

Geographic/climatic origins of top-ranking clones. Rank percentiles are average for both sites.

\begin{tabular}{|c|c|c|c|}
\hline $\begin{array}{c}\text { Clone growth rank } \\
\text { percentile }\end{array}$ & $\begin{array}{l}\text { DxN }{ }^{1} \text { clones, } M N \\
\text { provenance for } P \text {. } \\
\text { deltoides parents }\end{array}$ & $\begin{array}{c}\text { Clones } \\
{ }^{2} \text { southern/moderate } \\
\text { climatic origin }\end{array}$ & $\begin{array}{c}{ }^{3} \text { Other clones screened in } \\
\text { MN }\end{array}$ \\
\hline Top 10\% ( 6 clones) & 5 out of 6 clones & 1 out of 6 clones & zero \\
\hline Top 25\% (14 clones) & 10 out of 14 clones & 4 out of 14 clones & zero \\
\hline
\end{tabular}

${ }^{1}$ DxN clones are $P$. deltoides $x$. nigra hybrids with MN (Minnesota) provenance for the P. deltoides female parent, hybrids or female $P$. deltoides parent screened for survival, growth, and disease resistance in MN. ${ }^{2}$ are clones of more southerly or moderate climatic origins than MN and not screened in MN. ${ }^{3}$ (non-DxN or DxN of unknown provenance, but screened in MN).

Table 11

Spearman's correlation coefficients of clone ranks based on $\log _{10}$ tree bole volume between the two Indiana sites within four treatment types.

\begin{tabular}{lcc}
\hline \multicolumn{1}{c}{ Treatment type } & Spearman's correlation coefficient & $\mathrm{p}$-value \\
\hline Fertilizer & 0.5722 & $<0.0001$ \\
Fertilizer + Irrigation & 0.2430 & 0.0711 \\
Irrigation & 0.5542 & $<0.0001$ \\
No Treatment & 0.4682 & 0.0003 \\
\hline
\end{tabular}

Table 12

Ranks of NRRI clones common to current study in Indiana and previous clone trial in Minnesota (Nelson et al. 2018). Rank is ordered from highest value to lowest value. Bole volume values are across-site average of average site values.

\begin{tabular}{lccc}
\hline Clone & $\begin{array}{c}\text { Across both sites } \\
\log _{10} \text { Volume in current study }\end{array}$ & $\begin{array}{c}\text { Rank in } \\
\text { current } \\
\text { study }\end{array}$ & $\begin{array}{c}\text { Rank in previous MN } \\
\text { clone trial }\end{array}$ \\
\hline 99007071 & 4.18 & 2 & 24 \\
99038022 & 4.13 & 5 & 5 \\
20111315 & 4.11 & 9 & 4 \\
99038013 & 4.1 & 12 & 29 \\
99007116 & 4.08 & 14 & 9 \\
99059016 & 4.07 & 15 & 1 \\
99007115 & 4.03 & 18 & 20 \\
$9732-24$ & 3.99 & 24 & 6 \\
99098008 & 3.99 & 25 & 35 \\
$9732-11$ & 3.96 & 31 & 12 \\
M/R 502.37 & 3.95 & 32 & 51 \\
99105008 & 3.95 & 33 & 41 \\
NM6 & 3.94 & 37 & 59 \\
20111063 & 3.93 & 38 & 34 \\
99037049 & 3.92 & 40 & 36 \\
22091021 & 3.87 & 44 & 63 \\
99001111 & 3.83 & 46 & 47 \\
22091051 & 3.78 & 48 & 60 \\
NC14106 & 3.73 & 50 & 54 \\
\hline
\end{tabular}

Rank in current study based on $\log _{10}$ tree bole volume at age 3 in $\mathrm{cm}^{3}($ Table 9). Rank in MN study based on basal area at age 5 .

\section{Discussion}

The data clearly indicate that the fastest-growing $10 \%$ of the clones in this study are highly improved in comparison with commercial clones commonly used in the Midwestern United States (e.g., DN5 and NM6) and the rest of this collection of clones (Table 3). Site, treatment, clone, and site $x$ treatment and site $\mathrm{x}$ clone interactions all had significant effects on tree bole volume (Tables 4, 5). However, the clone effect was dominant, constituting $36 \%$ of the total variance. Site explained much less of the variance, and site $x$ clone somewhat less of the variance, than in a study on six sites in Minnesota that employed 19 of the same clones used in the present study (Nelson et al., 2018). There were significant treatment effects in the present study, but they were a relatively minor component of the overall variance. The broad-sense heritability estimate for the clonal population (0.46) is within the $0.21<\mathrm{H}^{2}<0.50$ range reported for Populus stem growth in several studies (reviewed in Riemenschneider et al., 1996).

We estimate a rotation of 5-7 years for the two sites in this study, based on mean annual increment per hectare versus that for 8 to 12-year rotations in Minnesota (D. Buchman, unpublished data, 2018). Thus, the three-year growth exhibited in this study represents approximately one-half of the rotation. In our experience, clone performance at half rotation is indicative of ultimate clonal rank at full rotation (Nelson et al., 2018). Kaczmarek et al. (2013) found that rank (based on treevolume measures) for faster-growing Populus clones at age 3 did not significantly change for the same clones at age 10 but did change for moderate to poorly performing clones. Thus, the results described here likely represent relative performance at full rotation, at least for the better-performing clones.

Fertilizer and Irrigation and the Fertilizer $x$ Irrigation interaction affected growth at one or both sites (Table 7). The response to Fertilization and Fertilization + Irrigation (29-31\%) was within the 20-60\% range reported in other studies of fertilization of Populus. Irrigation differentially increased growth on the two sites (Table 8), with trees at SWPAC benefitting more from irrigation than those at PPAC (Table 7). This is somewhat surprising, given that SWPAC has a finer texture soil and had $476 \mathrm{~mm}$ more natural precipitation per year over the three years of the study than did PPAC (Table 2). The test site at SWPAC had a slope of $10-18 \%$ versus only $0-2 \%$ at PPAC. SWPAC is also hotter than PPAC, and SWPAC soil has only half as much organic matter as PPAC (Table 2), all factors that may help explain the difference in irrigation response. The frequency and amount of irrigation was based on the judgment of a different expert agronomist at each site which also may explain some of the difference in response to irrigation. Even though there were significant treatment effects within and between sites, they may not be important in the overall interpretation of the results, as they explained a very small portion of the variance (Table 5).

The working paradigm for our breeding program, which is focused on the Midwestern United States, is that the scale of breeding investment that the bioenergy and bio-products industry is likely to support in the foreseeable future will 
preclude numerous breeding zones with narrowly adapted genotypes and small latitudinal bounds, i.e., specialists (Zalesny et al., 2009). Rather, the industry will require a collection of clones that exhibit a high degree of site adaptability and high yields over a range of approximately 38 to 48 degrees north latitude; i.e., generalists (Zalesny et al., 2009). This is different than the usual provenance-focused approach in traditional tree improvement programs with seed reproduction in pure species. The present study and Nelson et al. ( 2018) provide evidence that it may be possible to breed and select geographically robust inter-specific hybrid poplar clones, at least for DxN hybrids. Our hypothesis is that the $P$. nigra male component of DxN hybrids imparts broad adaptability to these genotypes. Regardless of the exact role of $P$. nigra in adaptability, genetic theory and empirical evidence point to increased heterozygosity and heterosis in interspecific genotypes, in comparison to pure species ( $\mathrm{Li}$ and $\mathrm{Wu}$ 1996). Heterozygosity and heterosis are associated with broader adaptability at the individual genotype level (Lerner 1954; Mitton and Grant 1984; Gillespie and Turelli 1989; Wu 1998). Unlike DxN hybrids, we would expect pure $P$. deltoides, the female component, to behave more like other pure species, wherein northern provenances would likely underperform southern provenances when moved southward to the latitude of the southern provenances (Eldridge et al., 1972; Ying and Bagley, 1976; Loehle, 1998). We will test the latter expectation with clonal trials in Minnesota, lowa, and Indiana that will be established in 2019 and include DxD and DxN hybrids.

DxN clones linked to Minnesota parentage and/or screening outperformed most clones of more southerly or otherwise more moderate climatic origins in the present study, which took place far south of Minnesota. Most of the clones derived from more moderate climates were in the lower $50^{\text {th }}$ percentile in rank. Only one was in the top $10^{\text {th }}$ percentile. The GWR DxN clones with Minnesota origin of the $P$. deltoides female parent performed well, even though, unlike the NRRI DxN clones, they were not screened in Minnesota. The NRRI DxN clones, with both Minnesota provenance origin and screening, also performed well on these Indiana sites, which were 5-9 degrees latitude south of where the screening took place in Minnesota.

Strong genetic control in DxN hybrids is also exhibited by the absence of rank change between the two Indiana sites (Table 11). Nelson et al. ( 2018) also found an absence of rank change and a low GxE interaction in relation to the clone effect in a study of 69 clones, $77 \%$ of which were DxN hybrids, on six sites in Minnesota. Furthermore, there was no rank change for the 19 clones common to this study and the Nelson et al. (2018) experiment (Table 12). In addition, three NRRI DxN clones were in the top $25^{\text {th }}$ rank percentile in both studies, in spite of the large latitudinal difference.

Neither Fertilization nor Irrigation had a significant effect on clone rank (Table 11). The combined Fertilizer + Irrigation treatment did have an effect on clone rank (Table 11), but $p$ for the Spearman coefficient was just above the 0.05 level, so this result is equivocal. The lack of any clear treatment effect on clone rank is again evidence of strong genetic control in this collection of clones, which is dominated by DxN hybrids, providing further corroboration of the broad adaptability of DxN clones.

An important synthesis of our previous study of clones on six sites in Minnesota (Nelson et al., 2018) and the current study is that broadly adapted hybrid poplar genotypes can be identified, particularly for DxN hybrids. Zalesny et al. ( 2009) found certain older clones that had stable biomass production across portions of Minnesota, Wisconsin, and lowa. European experience with Populus has been that natural hybrid DxN members of the P. $x$ canadensis taxon contain the most broadly adapted hybrid poplars for that temperate climate (CliftonBrown et al., 2019).

In addition to Nelson et al. (2018), the present study, and ongoing field tests in Minnesota, lowa, and Indiana, and further wide-range geographic experiments will be valuable in bolstering or refuting our hypothesis of broad adaptability in DxN hybrids. Data are available for coincident DxN clones from past field tests with cooperators in New York and Michigan and will be analyzed along with our other study results and reported in a future scientific paper that will address the discovery of geographically robust $\mathrm{DxN}$ clones over very broad latitudinal and longitudinal ranges.

A useful approach in further studies of clones adapted to wide geographic ranges would be to monitor phenology (shoot initiation and growth cessation). Such studies could lead to a better understanding of the physiological mechanisms behind the geographic robustness of these clones and refinements in clonal selection.

General conclusions can be drawn from this study. Clones in the top tenth percentile in volume growth were highly improved. The clonal effect was dominant in comparison to site, treatment, and all interaction effects. Clonal rank was the same on both sites regardless of treatment, except for the Fertilizer $\mathrm{x}$ Irrigation treatment. There was no rank change for clones common to this study in Indiana and a clone trial on six sites in Minnesota (Nelson et al., 2018), which are widely separated in latitude, providing further evidence of broad adaptability of DxN hybrids with female $P$. deltoides parents of Minnesota provenance. It may be possible to locate a breeding and screening center for such hybrids in Minnesota for deployment over a wider area, possibly eliminating the need for narrow breeding zones and allowing reduced intensity of testing at specific latitudes, thus saving time and money. Further field tests and analyses of other completed tests are planned to refine this hypothesis.

\section{Acknowledgements}

At Purdue University, this work was funded by a generous contribution from Hoosier Energy and a grant from the Mary S. Rice Farm Estate. Development of NRRI clones at the University of Minnesota's NRRI in Duluth was funded by the following: State of Minnesota appropriations to the Minnesota Hybrid Poplar Research Cooperative (MHPRC), State Special appropriations to the University of Minnesota Duluth Natural 
Resources Research Institute (NRRI), Minnesota Agricultural Utilization Research Institute, US DOE BETO Sun Grant Initiative Poplar Woody Crops Program contract \# DEFC36-05G085041; and the by the following companies through membership in the MHPRC-Verso Corporation, International Paper, Boise Cascade, Potlatch Corporation (now PotlatchDeltic), UPMBlandin, and Minnesota Power. Analysis and writing done at NRRI was funded by: USDA NIFA Agriculture and Food Research Initiative Competitive Grants Program Sustainable Bioenergy and Bioproducts Challenge Area grant \#2018-68005-27635. Clones were provided by the NRRI Poplar Program, US Forest Service Rhinelander Forestry Sciences Laboratory (Dr. Don Riemenschneider), and GreenWood Resources (GWR) (Rich Shuren). Parents from outside the NRRI program used in producing inter-specific hybrids at NRRI were from the University of Minnesota (Dr. Carl Mohn's program), GWR (Dr. Brian Stanton), University of Toronto (the late Dr. Louis Zsuffa), and lowa State University (the late Dr. Rick Hall). We thank Kathy Haiby (GWR) and Dr. Peggy Payne for delineating provenance origins for the GWR clones. We are also grateful to Matt Kraushar and the superintendents at the SWPAC and PPAC, Dennis Nowaskie and Jon Leuck, respectively, and their staff, particularly Angie Thompson and Bill Davis, for all of their hard work establishing, maintaining, and measuring the field trials. Anda Bellamy is gratefully acknowledged for editing the paper for journal submission. Two anonymous reviewers are acknowledged for materially improving the manuscript.

\section{References}

Clifton-Brown J, Harfouche A, Casler MD et al. ( 2019) Breeding progress and preparedness for mass-scale deployment of perennial lignocellulosic biomass crops switchgrass, miscanthus, willow and poplar. GCB Bioenergy 11:118-151.https://doi.org/10.1111/gcbb.12566

Coleman M, Tolsted D, Nichols T, Johnson WD, WeneEG, Houghtaling T (2006) Post-establishment fertilization of Minnesota hybrid poplar plantations. Biomass and Bioenergy 30:740-749. https://doi.org/10.1016/j.biombioe.2006.01.001

Coyle DR, Coleman MD (2005) Forest production responses to irrigation and fertilization are not explained by shifts in allocation. Forest Ecology and Management 208(1-3):137-152. https://doi.org/10.1016/j.foreco.2004.11.022

Dickmann D, Nguyen PV, Pregitzer KS (1996) Effects of irrigation and coppicing on above-ground growth, physiology, and fine-root dynamics of two fieldgrown hybrid poplar clones. Forest Ecology and Management 80:163-174. https://doi.org/10.1016/0378-1127(95)03611-3

Dobos R, Sinclair H Jr, Robotham M (2012) User Guide for the National Commod ity Crop Productivity Index (NCCPI) Version 2.0. Lincoln, Nebraska: USDA-NRCS, $80 \mathrm{p}$

Eldridge KG, Rout AR, Turnbull JW (1972) Provenance variation in the growth pattern of Populus deltoides. Australian Forest Research 5(4)

Gillespie JH, Turelli M (1989) Genotype-environment interactions and maintenance of polygenic variation. Genetics 121:129-138

Hansen E (1988) Irrigating short rotation intensive culture hybrid poplars. Biomass 16:237-250.https://doi.org/10.1016/0144-4565(88)90029-7

Kaczmarek DJ, Coyle DR, Coleman MD (2013) Survival and growth of a range of Populus clones in central South Carolina USA through age ten: Do early assessments reflect longer-term survival and growth trends? Biomass and Bioenergy 49:260-272. https://doi.org/10.1016/j.biombioe.2012.12.005

Krinard RM (1988) Volume equations for plantation cottonwood trees (Populus deltoides). USDA Forest Service, Southern Forest Experiment Station, SO347, 4 p https://doi.org/10.2737/SO-RN-347
Lerner IM (1954) Genetic homeostasis. Edinburgh and London: Oliver \& Boyd Ltd, $134 \mathrm{p}$

Li B, Wu R (1996) Genetic causes of heterosis in juvenile aspen: a quantitative comparison across intra- and inter-specific hybrids. Theoretical and Applied Genetics 93:380-391. https://doi.org/10.1007/BF00223180

Linder S (1989) Nutritional control of forest yield: Nutrition of trees. Falun, Sweden: The Marcus Wallenberg Foundation, pp 62-87

Loehle C (1998) Height growth rate tradeoffs determine northern and southern range limits for trees. Journal of Biogeography 25:735-742. https://doi.org/10.1046/j.1365-2699.1998.2540735.x

Mitton JB, Grant MC (1984) Associations among protein heterozygosity, growth rate, and developmental homeostasis. Annual Review of Ecology, Evolution, and Systematics 15:479-499.

http://doi.org/10.1146/annurev.es.15.110184.002403

Moffat AJ, Armstrong AT, Ockleston J (2001) The optimization of sewage sludge and effluent disposal on energy crops of short rotation hybrid poplar. Biomass and Bioenergy 20:161-169. https://doi.org/10.1016/S0961-9534(00)00073-8

Nelson ND, Berguson WE, McMahon BG, Cai M, Buchman DJ (2018) Growth performance and stability of hybrid poplar clones in simultaneous tests on six sites. Biomass and Bioenergy 118:115-125. https://doi.org/10.1016/i.biombioe.2018.08.007

Olson K, Lang J, Garcia-Paredes J, Majchrzak R, Hadley C, Woolery M et al. ( 2000) Average crop, pasture and forestry productivity ratings for Illinois soils. Urbana-Champaign, IL: Office of Research, College of Agricultural, Consumer and Environmental Sciences, University of Illinois

Riemenschneider DE, Stelzer HE, Foster GS (1996) Quantitative genetics of poplars and poplar hybrids. In: RF Stettler, HD Bradshaw Jr., PE Heilman and TM Hinckley (eds) Biology of Populus and its implications for management and conservation - Part I, Chapter 7. Ontario, Canada: NRC Research Press, National Research Council of Canada, Ottawa, pp 159-181

Samuelson LJ, Stokes TA, Coleman MD (2007) Influence of irrigation and fertilization on transpiration and hydraulic properties of Populus deltoides. Tree Physiology 27(5):765-774. https://doi.org/10.1093/treephys/27.5.765

Stanton B, Eaton J, Johnson J, Rice D, Schuette B, Moser B (2002) Hybrid poplar in the Pacific Northwest: the effects of market-driven management. Journal of Forestry 100(4):28-33. https://doi.org/10.1093/jof/100.4.28

U.S. Department of Energy (US DOE) (2016) 2016 Billion-Ton Report: Advancing Domestic Resources for a Thriving Bioeconomy. In: Langholtz MH, BJ Stokes and LM Eaton (Leads) Volume 1: Economic Availability of Feedstocks. Oak Ridge, TN: ORNL/TM-2016/160, Oak Ridge National Laboratory. http://doi.org/10.2172/1271651.

van den Driessche R, Rude W, Martens L (2003) Effect of fertilization and irrigation on growth of aspen (Populus tremuloides Michx.) seedlings over three seasons. Forest Ecology and Management 186:381-389. https://www.sciencedirect.com/science/article/pii/S0378112703003062

White CC, Adams WT, Neale DB (2007) Forest Genetics. Wallingford Oxfordshire, United Kingdom: CAB International, $682 \mathrm{p}$, https://doi.org/10.1079/9781845932855.0000

Wu R (1998) The detection of plasticity genes in heterogeneous environments. Evolution 52:967-977. https://doi.org/10.1111/j.1558-5646.1998.tb01826.x

Ying CC and WT Bagley (1976) Genetic variation of eastern cottonwood in an eastern Nebraska provenance study. Silvae Genetica 25(2):67-73.

Zalesny RS, Hall RB, Zalesny JA, McMahon BG, Berguson WE, Stanosz GR (2009) Biomass and genotype $x$ environment interactions of Populus energy crops in the Midwestern United States. BioEnergy Research 2:106-122. https://doi.org/10.1007/s12155-009-9039-9 